\title{
Editorial
}

\section{A New Feature for the Journal of Neuroscience: New Directions in Neuroscience}

From its inception in 1980, the Journal of Neuroscience has focused on publishing original research articles representing the highest quality work being done in the field. Priority is placed on articles that report the application of novel methods that give new insights of broad interest into neural mechanisms, at all levels of organization, all phyla, all stages of development and aging, and in normal and diseased nervous systems. It is a broad mandate, but one that is appropriate to serving the many communities within the Society for Neuroscience and beyond.

But how does a broad readership such as ours stay abreast of this range of research? This is not a new problem for our day. On reviewing the publications on electromagnetism that had come out after Oersted discovered the magnetic effect of electric current in 1820, Michael Faraday reported that "it took great labor and fatigue to go through systematically everything that had appeared in journals and elsewhere" in just the eight subsequent months.

Despite the advantages of the internet, present day neuroscientists can feel some of that same "labor and fatigue" in keeping up with the ever more torrid pace of current research. To assist in this effort, the Journal of Neuroscience is initiating a new series of minireviews, called "New Directions in Neuroscience." These reviews will be concise, in order that they can be timely. Each set will be focused on a new technology or new field of research that promises to take neuroscience in significant new directions. They will be written to be readable by all neuroscientists, to disseminate the essence of new methods and new fields to the range of workers within neuroscience. And they will be critical, helping the reader to sort the real stuff from the hype.

There is no better time to initiate this series than now, with the publication in February of this year of the initial draft of the Human Genome. What is the significance of this big step forward for neuroscience? We have asked Floyd Bloom, former editor of Science and chair of the publications committee, to host this first series with a set of reviews under the title of "Genomics and Proteomics." This issue begins with his Introduction, followed by the informative and insightful reviews by a panel of outstanding pioneers in the artforms of this brave new world.

Gordon M. Shepherd

Editor-in-Chief 